\title{
AS MIGRAÇÕES PARTIDÁRIAS E A CORRELAÇÃO DE FORÇAS NA CÂMARA DOS DEPUTADOS (1995-2006)
}

\author{
Marcelo Costa Ferreira
}

\begin{abstract}
RESUMO
A literatura acadêmica enfatiza o fato de que as elevadas taxas de migração partidária política na Câmara dos Deputados descaracterizariam o sistema partidário brasileiro e provocariam instabilidade política, pois tornariam instáveis as coalizões no interior do parlamento brasileiro. A questão de pesquisa deste artigo é analisar a relação entre a migração e a correlação de forças no interior da Câmara dos Deputados. Para fazê-lo, consideramos a variação diária das migrações partidárias, mensuradas indiretamente pela variação dos tamanhos das bancadas, entre 1995 e 2006, comparando-as com as composições partidárias das mesas diretoras e das presidências das Comissões de Constituição e Justiça e da de Finanças e Tributação. O principal achado deste estudo é que a elevada migração partidária tem impacto sobre as pequenas bancadas partidárias, mas não afeta os tamanhos das quatro maiores bancadas em uma proporção que altere a correlação de forças no interior da Câmara dos Deputados. Tal descoberta contraria a relação proposta pelos críticos da migração partidária no Brasil, entre elevada migração e instabilidade política na Câmara dos Deputados.
\end{abstract}

PALAVRAS CHAVE: migração partidária; política brasileira; Câmara dos Deputados.

\section{INTRODUÇÃO ${ }^{1}$}

Este artigo tem como objetivo analisar a relação entre a "migração partidária" e "estabilidade política" na Câmara dos Deputados. Pretendemos verificar se as alterações nas bancadas partidárias no período de 1995 a 2006 provocaram alterações na correlação de forças na citada casa parlamentar. Se essa relação de fato existir, um dos aspectos negativos da movimentação partidária seria confirmado, ou seja, que a fraqueza institucional dos partidos políticos brasileiros, que provoca a migração, afetaria a estabilidade da Câmara dos Deputados.

\footnotetext{
1 Gostaria de agradecer aos dois pareceristas anônimos pelos excelentes comentários e pela leitura minuciosa que foi feita deste artigo, cuja qualidade foi incrementada de maneira significativa. Também gostaria de ressaltar minha gratidão pelo apoio da Pró-Reitoria de Pesquisa da Universidade Federal de São Paulo (Unifesp) às atividades de pesquisa em Ciências Humanas. A pesquisa em que este trabalho insere-se utiliza informações da Câmara dos Deputados. Contudo, todas as análises das informações aqui empregadas são de minha autoria e responsabilidade.
}

A migração partidária tem sido analisada com muito ceticismo por muitos acadêmicos ${ }^{2}$. Eles criticam a baixa fidelidade partidária, pois a migração seria não só um engodo ao eleitor, mas também um ato moralmente reprovável, conforme destaca Roma: "O debate no Brasil sobre a infidelidade partidária limita-se muitas vezes às questões normativas em torno de um imperativo segundo o qual o representante deve manter-se filiado sempre a um partido político durante o exercício do seu mandato, quando não, durante toda a sua carreira. Esse princípio, no qual os críticos da migração apóiam, incentiva a proposição de inúmeros projetos de reforma da legislação, em especial o estabelecimento de regras que forcem os mandatários a permanecerem leais à sua legenda" (ROMA, 2007, p. 378-379).

A migração entre os partidos e a instabilidade política é um aspecto muito relevante, mas que foi muito pouco analisado na literatura acerca da

\footnotetext{
2 Quatro excelentes revisões da literatura podem ser encontradas em Araujo (2000), Diniz (2000), Freitas (2008)
} e Schmitt (1999). 
migração partidária. Um dos raros autores que abordou esse tópico, observa que a existência de uma correlação de forças muito assimétrica entre o Executivo e o Legislativo Federal que faria que esse fenômeno não afetasse a governabilidade (DINIZ, 2000, p. 46). Em resumo, a relação entre governabilidade e migração partidária baseada em dados empíricos é inexistente na literatura acadêmica e este tópico não costuma ser abordado em detalhe.

Segundo alguns autores, a migração partidária gera um impacto negativo na estabilidade governamental no parlamento nacional brasileiro. Esse aspecto é pesquisado no estudo de Melo (2004), segundo o qual "a mudança de partido tornou-se endêmica no cenário político brasileiro. $\mathrm{E}$, por isso, não pode ser tratada como parte de nosso folclore, ou como uma curiosidade a mais neste país tão pleno de práticas desinstitucionalizadas. Transformada em prática corrente, a troca de legenda passou a vigorar como instrumento suplementar de modificação da correlação de forças no Congresso" (idem, p. 161). Da mesma forma, Roma afirma que, "enfim, infidelidade partidária deveria acarretar grave problema para o funcionamento da Câmara Baixa, tal como se teoriza, tomando-se como referência outros países. Essas suposições, porém, ainda não foram averiguadas porque a literatura focaliza a magnitude e as causas da migração partidária, e não as suas conseqüências para o processo legislativo" (ROMA, 2007, p. 353).

$\mathrm{O}$ argumento deste trabalho, porém, consiste em demonstrar que, apesar da significativa migração partidária, ela não alteraria a composição de poder porque não afeta todos os partidos da mesma maneira. Em outras palavras: se a migração partidária, mensurada pela variação da bancada partidária dia-a-dia, alterasse a correlação de forças na Câmara dos Deputados, conforme previsto por Melo, ocorreria uma significativa alteração na composição dos integrantes da Mesa Diretora da Câmara dos Deputados, como também nas presidências das Comissões de Constituição e Justiça e na de Finanças e Tributação. Isso ocorreria em função de regra no processo legislativo da Câmara dos Deputados, que prescreve que os cargos mais importantes na hierarquia parlamentar sejam ocupados de acordo com o tamanho da bancada partidária, de acordo com o Artigo $7^{\circ}$, Inciso I, do Regimento Interno da Câmara dos
Deputados, por sua vez de acordo com a Resolução 45 da Câmara dos Deputados, de 2006.

Por exemplo: a Comissão de Constituição e Justiça (CCJC) e a Comissão de Finanças e Tributação (CFT) são as que mais atraem os parlamentares com força política, devido a sua centralidade no processo legislativo: nenhum projeto de lei tramita na Câmara dos Deputados se não tiver o parecer favorável no que tange à constitucionalidade, tanto na CCJC quanto no aspecto orçamentário, dado o prescrito no Artigo 139, Inciso II, alíneas b e c: "Excetuadas as hipóteses contida no artigo 34, a proposição será distribuída [...] b) quando envolver aspectos financeiros ou orçamentários públicos, à Comissão de Finanças e Tributação, para exame de compatibilidade ou adequação orçamentária; c) obrigatoriamente, à Comissão de Constituição, Justiça e Cidadania, para o exame dos aspectos de constitucionalidade, legalidade, juridicidade, regimentalidade e de técnica legislativa [...]" (CÂMARA DOS DEPUTADOS, 2008). Em outras palavras: essas comissões são destacadas como instâncias principais no processo legislativo, sendo que a sua respectiva titularidade indica posição de poder não só para o parlamentar que a ocupa como também para o respectivo partido.

$\mathrm{O}$ argumento aqui apresentado é que existe significativa variação e migração partidária. Todavia, a mesma concentra-se nos pequenos partidos, que pouco participam da partilha dos postos de poder no Congresso. Os grandes partidos, na maior parte, não sofrem alteração nos tamanhos das bancadas de modo a perderem ou terem alteradas suas posições de poder. Essa migração não afeta os tamanhos das quatro maiores bancadas de modo a sugerir que esta movimentação muito dinâmica afete a correlação de forças no interior da Câmara dos Deputados. A migração partidária é um fenômeno quase diário na Câmara enquanto a eleição da Mesa Diretora ocorre, de acordo com as atuais regras, a cada dois anos.

Todavia, ressalto, o foco deste artigo é exclusivamente a relação entre migração partidária e a correlação de forças na Câmara dos Deputados. Se a migração afetasse a eleição da Mesa, haveria um padrão de instabilidade na composição partidária da Mesa Diretora da Câmara dos Deputados. Contudo, a representação partidária da Mesa sempre corresponde à coalizão governamental. O único caso em que isso não ocorreu foi a atípica 
eleição do então Deputado Federal Severino Cavalcanti (PPB-PE) à Presidência da Câmara dos Deputados em 2005, quando a candidatura governista foi representada pelos Deputados Federais Virgílio Guimares (PT-MG) e Luis Eduardo Greenhalgh (PT-SP) $)^{3} \mathrm{em}$ um explícito racha na coalizão do governo.

A próxima seção apresenta a forma pela qual e migração partidária foi mensurada, enquanto seguinte apresenta a análise das informações.

\section{A MENSURAÇÃO DA MIGRAÇÃO PARTI- DÁRIA}

Utiliza-se a variação no tamanho da bancada parlamentar como variável aproximada (proxy), da migração partidária 4 . O tamanho da bancada partidária em cada dia na Câmara dos Deputados foi registrado entre 1995 e 2006, permitindo analisar a variação das quantidades de deputados federais por partido político. Neste caso, foram analisados quatro partidos, PMDB, PSDB, PT, PFL $^{5}$ e os pequenos partidos foram todos agregados em uma só bancada, "outros partidos", para efeito de análise de dados.

A agregação dos pequenos partidos em apenas uma macro bancada segue critérios de relevância teórica e parcimônia na apresentação dos dados (TUFTE, 2001). Pequenos partidos só têm alguma força política se agregados em um bloco parlamentar com muitos deputados, que os permita disputar uma vaga na mesa diretora da Câmara dos Deputados, o que só ocorre em situações muito específicas, como a da eleição bianual da citada mesa. As maiores bancadas disputam poder, algo que os partidos nanicos raramente experimentam, já que é muito raro terem uma capacidade de coesão que ameace as quatro maiores bancadas ou blocos partidários na Câmara dos Deputados.

Outro aspecto é que, de acordo com os critérios de apresentação visual de Tufte (idem), um gráfico é melhor visualizado quanto menor for a

\footnotetext{
3 Respectivamente: Partido Progressista Brasileiro e Partido dos Trabalhadores.

4 O trabalho de Marenco (2001), por exemplo, trata do termo "migração" como lealdade partidária.

5 Respectivamente: Partido do Movimento Democrático Brasileiro, Partido da Social Democracia Brasileira, Partido dos Trabalhadores e Partido da Frente Liberal.
}

quantidade de informações que o mesmo apresenta. Logo, a agregação dos pequenos partidos em uma única bancada para fins de análise de dados justifica-se dada a enorme quantidade de partidos nanicos - cujo enorme quantitativo é inversamente proporcional a sua respectiva minúscula força política - e a necessidade de apresentar de maneira clara as evidências empíricas pertinentes ao argumento deste trabalho.

Logo, estatísticas descritivas e a análise das variações dos tamanhos das bancadas entre 19951999, 1999-2002 e 2003-2006 foram efetuadas e comparadas com a composição partidária da Mesa Diretora e das Comissões de Constituição e Justiça e de Finanças e Tributação da Câmara dos Deputados. As quatro maiores bancadas, PSDB, PMDB, PT e PFL foram analisadas em contraposição ao agregado do grupo dos pequenos partidos.

Os principais partidos teriam um padrão de migração partidária diferente dos pequenos partidos. Logo, os principais cargos na Câmara dos Deputados não teriam a sua distribuição afetada tendo em vista o princípio de que as posições de poder nas instâncias decisórias no poder Legislativo federal são ocupadas prioritariamente pelos maiores partidos. Em outras palavras: a hipótese nula é que a migração partidária causa instabilidade governamental porque altera os tamanhos das maiores bancadas no que toca o jogo de forças políticas nas três citadas instâncias legislativas, ou seja, o contrário do argumento de que a migração partidária tem um efeito negativo sobre o sistema partidário no interior da Câmara dos Deputados.

\section{A MIGRAÇ̃̃O PARTIDÁRIA E A COMPO- SIÇÃO DAS INSTÂNCIAS DE PODER NA CÂMMARA DOS DEPUTADOS}

Dois padrões de coalizão governamental foram observados nas três legislaturas aqui analisadas, 1995-1999, 1999-2002 e 2002-2006, descritos na Tabela 1. O primeiro foi composto por PSDB, PMDB e PFL, aliança que permitiu o exercício de governo do então Presidente Fernando Henrique Cardoso, entre 1995 e 2002. O segundo consistiu em uma aliança entre o PT, o PMDB e diversos outros pequenos partidos como apoio à Presidência de Luiz Inácio Lula da Silva. Como a migração partidária afetou as citadas coalizões governamentais? 
TABELA 1 - VARIAÇÕES NOS TAMANHOS DAS BANCADAS PARTIDÁRIAS (1995-1999 E 2003-2006)

\begin{tabular}{|l|ccc|ccc|ccccccccc|}
\hline Partido & \multicolumn{3}{c|}{ PMDB } & \multicolumn{3}{c|}{ PSDB } & \multicolumn{3}{c|}{ PFL } & \multicolumn{3}{c|}{ PT } & \multicolumn{3}{c|}{ OUPART } \\
\hline Legislatura & $1995-$ & $1999-$ & $2002-$ & $1995-$ & $1999-$ & $2002-$ & $1995-$ & $1999-$ & $2002-$ & $1995-$ & $1999-$ & $2002-$ & $1995-$ & $1999-$ & $2002-$ \\
& 1999 & 2002 & 2006 & 1999 & 2002 & 2006 & 1999 & 2002 & 2006 & 1999 & 2002 & 2006 & 1999 & 2002 & 2006 \\
Média & 95 & 94,5 & 78 & 85 & 99,6 & 53 & 101 & 101 & 64 & 49 & 58,4 & 88 & 178 & 157 & 223 \\
Mediana & 97 & 96 & 78 & 86 & 101 & 52 & 100 & 101 & 63 & 50 & 59 & 90 & 178 & 152 & 224 \\
CV $^{1}$ (\%) & 6,3 & 5,0 & 7,7 & 11,7 & 4,6 & 7,5 & 6,9 & 5,15 & 7,8 & 1,7 & 3,2 & 4,5 & 6,2 & 8,7 & 3,1 \\
Intervalo & 24 & 20 & 25 & 37 & 16 & 18 & 24 & 17 & 20 & 7 & 12 & 13 & 45 & 51 & 27 \\
Minimo & 83 & 82 & 66 & 63 & 90 & 46 & 88 & 94 & 57 & 44 & 49 & 81 & 161 & 136 & 209 \\
Maximo & 107 & 102 & 91 & 100 & 106 & 64 & 112 & 111 & 77 & 51 & 61 & 94 & 206 & 187 & 236 \\
$N^{2}$ & 300 & 331 & 325 & 300 & 331 & 325 & 300 & 331 & 325 & 300 & 331 & 325 & 300 & 331 & 325 \\
\hline
\end{tabular}

FONTE: o autor, a partir de Câmara dos Deputados (2007).

1. O Coeficiente de Variação é a divisão do desvio-padrão pela respectiva média de uma distribuição. No caso da Tabela 1, o CV está apresentado na forma percentual (FONSECA \& MARTINS, 1982, p. 127-128).

2.Quantidades de alterações no tamanho da bancada partidária.

A Tabela 1 descreve as estatísticas descritivas da migração partidária em dois momentos. No primeiro, o mandato inicial de Fernando Henrique Cardoso. O PSDB, PMDB e PFL formavam a coalizão de apoio ao governo, enquanto o PT era oposição; no segundo, a aliança PT-PMDB era a base parlamentar de apoio a Luis Inácio Lula da Silva.

A descrição da variação confirma parcialmente alguns aspectos do fenômeno migratório apontado pela literatura ${ }^{6}$. No período de 1995-1999, o Coeficiente de Variação percentual das alterações do tamanho da bancada do Partido dos Trabalhadores foi ínfimo. Todavia, apesar da varia-

\footnotetext{
6 As estatísticas descritivas da Tabela 1 são coerentes com o achado de Marenco e Serna: "[...] que diferenças observadas nos padrões de carreira política possam ser explicadas pelas variações no perfil social e pelos recursos individuais dos candidatos eleitos por cada legenda partidária: os partidos à esquerda, de origem ideológica $\mathrm{e}$ mais longevos, recrutam suas bancadas predominantemente no setor público, na classe média assalariada, entre sindicalistas, lideranças associativas e lideranças de movimentos sociais, os quais, por depender da estrutura organizacional partidária e associativa para compensar a carência de recursos eleitorais próprios, terminam adotando estratégias baseadas em carreiras partidárias endógenas. No extremo oposto, partidos conservadores apresentam padrões de recrutamento social mais elitista e tradicional, compondo suas bancadas entre proprietários urbanos e rurais e profissionais liberais dotados de recursos materiais e de reputação personalizada, com menor dependência da estrutura organizacional partidária, seguindo carreiras políticas laterais, descontínuas e com menos lealdade à filiação partidária” (MARENCO \& SERNA, 2001, p. 93-94).
}

ção em termos absolutos ter sido maior entre a bancada dos partidos pequenos, a variação percentual no tamanho da bancada foi muito maior no PSDB.

Nas três legislaturas percebe-se um padrão quase constante em 300 trocas de partido. As mudanças no interior de cada partido têm uma distribuição bem simétrica, mas as distintas conjunturas políticas explicam muitas das diferenças encontradas entre a oposição e o governo. Outro aspecto a ser mencionado é a diferença entre a coalizão PSDB-PMDB-PFL nas legislaturas 19951999 e 1999-2002 em comparação com o período de 2002-2006 no padrão de migração. Ela reside no aumento da variação dos tamanhos das bancadas do PT e dos "outros partidos", a macro bancada dos pequenos. Esse processo faz parte não só da ascensão da coalizão de centro-esquerda, mas também da incorporação dos pequenos partidos ao bloco de apoio ao governo.

O PMDB é peça-chave no processo de governabilidade e construção de maiorias na Câmara dos Deputados. Entre 1995 e 2006, ele teve em média 95 deputados, sendo a mediana muito próxima deste valor. O baixo coeficiente de variação também atesta que as oscilações no tamanho da bancada do PMDB seguem um padrão pouco variável.

O PSDB, assim como o PFL, teve um número expressivo de parlamentares entre 1995 e 2002, tendo uma queda no período 2002-2006. Contudo, não foi a migração partidária que afetou a perda de hegemonia, mas sim a eleição de uma nova coalizão entre o PMDB e o PT em 2003. O PT 
teve um aumento no número de parlamentares em 2003 e o coeficiente de variação também aumentou.

Os outros partidos somam uma grande bancada, como agregada de artifício metodológico, cujo tamanho apresenta grande variação. As mesas diretoras da casa, contudo, continuam concentradas nos maiores partidos da Câmara dos Deputados entre 1995 e 2006. A migração partidária existe de modo significativo, mas afeta de modo muito diferente os partidos com força política para participar da Mesa Diretora ${ }^{7}$, que são as quatro maiores bancadas com número de deputados federais, em comparação com os outros pequenos partidos.
A Tabela 2 apresenta os tamanhos das bancadas ano a ano, sendo que à esquerda é apresentado o quantitativo por bancada, e à direita a posição no ranking das quatro maiores bancadas. Na primeira legislatura analisada, o PMDB tinha a maior bancada em 1995, posição que foi perdida para o PFL em 1999. Entre 1999 e 2002, o PSDB oscilou entre a segunda e a terceira maior bancada, enquanto o PFL ocupou a primeira posição - excluindo o ano de 2000, em que o PSDB teve a maior bancada. Em todos os anos, o tamanho do coletivo de Deputados Federais do PT foi praticamente o mesmo, e este fato é coerente com a posição defendida na literatura de que os partidos de esquerda tendem a ser menos afetados pela migração partidária.

TABELA 2 - TAMANHOS E RANKING DAS QUATRO MAIORES BANCADAS (1995-2006)

\begin{tabular}{|l|ccccccccc|}
\hline & \multicolumn{7}{c|}{ Tamanho da bancada } & \multicolumn{5}{c|}{ Ranking das bancadas } & Data \\
\hline & PMDB & PSDB & PT & PFL & PMDB & PSDB & PT & PFL & 20.12 .1995 \\
1995 & 97 & 80 & 49 & 95 & 1 & 3 & 4 & 2 & 31.12 .1996 \\
1996 & 91 & 83 & 49 & 99 & 2 & 3 & 4 & 1 & 29.12 .1997 \\
1997 & 86 & 96 & 50 & 110 & 3 & 2 & 4 & 1 & 28.12 .1998 \\
1998 & 89 & 93 & 50 & 111 & 3 & 2 & 4 & 1 & 10.12 .1999 \\
2000 & 99 & 101 & 60 & 106 & 3 & 2 & 4 & 1 & 31.12 .2000 \\
2001 & 96 & 104 & 57 & 101 & 3 & 1 & 4 & 2 & 28.12 .2001 \\
2002 & 88 & 94 & 59 & 95 & 3 & 2 & 4 & 1 & 31.12 .2002 \\
2003 & 85 & 93 & 57 & 94 & 3 & 2 & 4 & 1 & 30.12 .2003 \\
2004 & 77 & 51 & 90 & 67 & 2 & 4 & 1 & 3 & 31.12 .2004 \\
2005 & 76 & 48 & 88 & 61 & 2 & 4 & 1 & 3 & 21.12 .2005 \\
2006 & 82 & 53 & 82 & 62 & 1 & 3 & 1 & 2 & 10.10 .2006 \\
\hline
\end{tabular}

FONTE: o autor, a partir de Câmara dos Deputados (2006).

A análise das informações nas tabelas 1 e 2 não corrobora nenhuma associação positiva entre migração partidária e instabilidade política. Todos os cargos na Mesa Diretora da Câmara dos Deputados são preenchidos por congressistas que pertencem aos partidos majoritários. Porém, existem diferenças entre o perfil parlamentar dos deputados que ocupam cargos na Mesa Diretora. De um lado, a Presidência da Câmara ${ }^{8}$, a Primeira Vice-Presidência ${ }^{9}$, a Segunda Vice-Presidência, o

\footnotetext{
7 É o órgão de uma casa parlamentar composto pelo Presidente, um Vice ou um Primeiro Secretário, além de outros integrantes.

8 Ela tem papel crucial na condução do processo legislativo e na administração geral da casa parlamentar.

9 O Primeiro Vice-Presidente, assim como o Segundo, da Câmara dos Deputados tem como objetivo substituir o presidente da Casa Parlamentar nas ausências dele.
}

Primeiro Secretário ${ }^{10}$, o Quarto Secretário ${ }^{11}$ e os presidentes das CCJC e CFT são ocupados pelos partidos da base do governo; do outro, Segundo Secretário $^{12}$ e Terceiro Secretário ${ }^{13}$ são ocupados por partidos que não pertencem à coalizão governamental, mas que constituem blocos parti-

10 Consiste na representação institucional da casa parlamentar.

11 Ela concentra a parte administrativa da Câmara dos Deputados, principalmente na parte de auxílio moradia e gestão dos apartamentos funcionais dos deputados federais em Brasília.

12 A Segunda Secretaria tem como objetivo receber a correspondência oficial da casa parlamentar.

13 A Terceira Secretaria serve como órgão de Segunda Instância em relação à Diretoria Geral da Câmara dos Deputados, que é responsável pela gestão cotidiana dos serviços administrativos. 
dários que garantem força política que os permite pleitear um espaço na Mesa Diretora. O primeiro grupo fica com os partidos com maior força política, enquanto no segundo grupo é alocado aos pequenos partidos que barganham na disputa eleitoral pela Presidência da Câmara dos Deputados.

A Presidência da Câmara dos Deputados foi exercida no biênio 1995-1996 por Luis Eduardo Magalhães, PFL-BA, e em 1997-1998, por Michel Temer (PMDB-SP). A Comissão de Constituição e Justiça, em 1995-1996, por Roberto Magalhães, e em 1997-1998, pelo PMDB-SP e PSDB-SP. Existem três padrões de alteração nos tamanhos das bancadas partidárias e na correlação de forças no Congresso. O primeiro corresponde ao período de 1995-1999. Era o primeiro mandato do então presidente Fernando Henrique Cardoso, cuja coalizão no Congresso era formada pela aliança entre o PSDB e o PFL, atual Democratas (DEM).

TABELA3 - COMPOSIÇÃO PARTIDÁRIA DAMESA DIRETORA E DAS COMISSÕES CCJR E CFT (1995-2006)

\begin{tabular}{|c|c|c|c|c|c|c|c|c|c|c|c|c|}
\hline & 1995 & 1996 & 1997 & 1998 & 1999 & 2000 & 2001 & 2002 & 2003 & 2004 & 2005 & 2006 \\
\hline Presidência & \multicolumn{2}{|c|}{ PFL } & \multicolumn{4}{|c|}{ PMDB } & \multicolumn{2}{|c|}{ PSDB } & PT & PT & PP/PC do B & PCdoB \\
\hline $1^{\circ}$ Vice & \multicolumn{2}{|c|}{ PMDB } & \multicolumn{2}{|c|}{ PFL } & \multicolumn{2}{|c|}{ PFL } & \multicolumn{2}{|c|}{ PFL } & \multicolumn{2}{|c|}{ PFL } & PFL & PFL \\
\hline $2^{\circ}$ Vice & \multicolumn{2}{|c|}{ PPB } & \multicolumn{2}{|c|}{ PPB } & \multicolumn{2}{|c|}{ PPB } & \multicolumn{2}{|c|}{ PMDB } & \multicolumn{2}{|c|}{ PSDB } & $\mathrm{PP}$ & PP \\
\hline $1^{\circ}$ Secretário & \multicolumn{2}{|c|}{ PSDB } & \multicolumn{2}{|c|}{ PSDB } & \multicolumn{2}{|c|}{ PSDB } & \multicolumn{2}{|c|}{ PPB } & \multicolumn{2}{|c|}{ PMDB } & PMDB & PL \\
\hline $2^{\circ}$ Secretário & \multicolumn{2}{|c|}{ РТВ } & \multicolumn{2}{|c|}{ РTB } & \multicolumn{2}{|c|}{ РТВ } & \multicolumn{2}{|c|}{ РTB } & \multicolumn{2}{|c|}{ PPB } & РTB & РTB \\
\hline $3^{\circ}$ Secretário & \multicolumn{2}{|c|}{ PPB } & \multicolumn{2}{|c|}{ PT } & \multicolumn{2}{|c|}{ PT } & \multicolumn{2}{|c|}{ PT } & \multicolumn{2}{|c|}{ РTB } & PSDB & PSDB \\
\hline $4^{\circ}$ Secretário & \multicolumn{2}{|c|}{ PMDB } & \multicolumn{2}{|c|}{ PFL } & $\mathrm{PF}$ & $=L$ & \multicolumn{2}{|c|}{ PFL } & \multicolumn{2}{|c|}{ PFL } & PL & PL \\
\hline CCJR & PFL & PM & IDB & PSDB & PFL & & SDB & PFL & PT & PT & PT & $\mathrm{PT}$ \\
\hline CFT & PMDB & PPB & PSDB & PMDB & PSDB & $\mathrm{PFL}$ & PMDB & PMDB & PFL & PMDB & PMDB & PMDB \\
\hline
\end{tabular}

FONTE: o autor, a partir de Câmara dos Deputados (2007).

Na legislatura citada, a Presidência da Câmara foi exercida por Michel Temer, do PMDB-SP, entre 1999-2000, enquanto no período de 2001-2002 a mesma teve como ocupante Aécio Neves, do PSDB-MG. Percebe-se que ambas foram preenchidas por parlamentares ora dos maiores partidos, PMDB e PSDB, ora por deputados federais representantes dos dois maiores colégios eleitorais do Brasil, São Paulo e Minas Gerais. A Primeira Vice-Presidência da Câmara dos Deputados foi sempre ocupada pelo PFL, em 1999 e 2002, respectivamente, por parlamentares do estado do Piauí ou da Paraíba, ambos representantes de estados da região Nordeste, que no agregado como região geográfica desempenha um papel fundamental em uma eleição presidencial devido ao tamanho do seu eleitorado ${ }^{14}$.

No período de 1995-1999, apresentado pelo Gráfico 1, a citada legislatura, na Câmara dos Deputados, teve um padrão bem delimitado entre as

\footnotetext{
14 Segundo o sítio do Tribunal Eleitoral Superior (2009), o eleitorado da região Nordeste compõe $27 \%$ do total brasileiro, o que o caracteriza como o segundo maior do
} Brasil. três maiores bancadas partidárias que apoiavam o governo Fernando Henrique Cardoso. A bancada do somatório dos pequenos partidos reduziu-se no decorrer do primeiro mandato deste, já o tamanho do Partido dos Trabalhadores foi constante. Além disso, a literatura sobre migração partidária destaca que os partidos de esquerda tendem a ter menor migração que os de direita, e os partidos de base clientelística ou conservadora tendem a ter maiores taxas de migração, por sua vez responsáveis pela quase totalidade do agregado dos outros partidos. O PMDB perde a condição de primeira bancada no final de 1995 para o PFL, cujo crescimento é crescente juntamente com a do PSDB até dezembro de 1998. Todavia, a hegemonia da aliança PSDB-PFL-PMDB em momento algum foi atacada, apesar de ocorrerem variações no interior desse agregado.

Os anos de 2005 e 2006 foram totalmente atípicos no processo de eleição para a Presidência da Câmara dos Deputados. O princípio de que as maiores bancadas da Câmara dos Deputados têm primazia na escolha da Presidência e dos postos da Mesa Diretora e das Comissões Temáticas não foi seguido devido ao racha na coalizão governamental PT-PMDB. João Paulo, (PT-SP) que exer- 
ceu a Presidência da Câmara dos Deputados no Biênio 2003-2004, foi sucedido por Severino Cavalcanti (PP-PI), em 2005, e Aldo Rebelo, em 2006 - ambos de partidos que não eram das quatro maiores bancadas partidárias. Contudo, esse processo não foi provocado pelos padrões de migração partidária.

O caso do Partido dos Trabalhadores é exemplar da mudança de um partido de oposição para o governo. Enquanto não havia assumido o poder Executivo federal, o PT tinha o menor desvio padrão entre os partidos analisados, o que se refere à constatação de que partidos ideológicos têm uma variação no tamanho da bancada menor que agremiações partidárias ditas fisiológicas, ou de quadros, isto é, os parlamentares de esquerda tendem a ser mais leais às suas respectivas agremiações partidárias que os congressistas de partidos conservadores, coerente com o argumento desenvolvido em Marenco e Serna (2007, p. 105). Todavia, o desvio padrão aumentou para mais ou menos quatro deputados federais quando a coalizão de centro-esquerda assumiu o poder, valor este próximo do de outros partidos com histórico governista: PFL, PSDB e PMDB.

\section{GRÁFICO 1 - VARIAÇÕES DIA-A-DIANOS TAMANHOS DAS BANCADAS PARTIDÁRIAS NA CÂMARA DOS} DEPUTADOS (1995-1998)

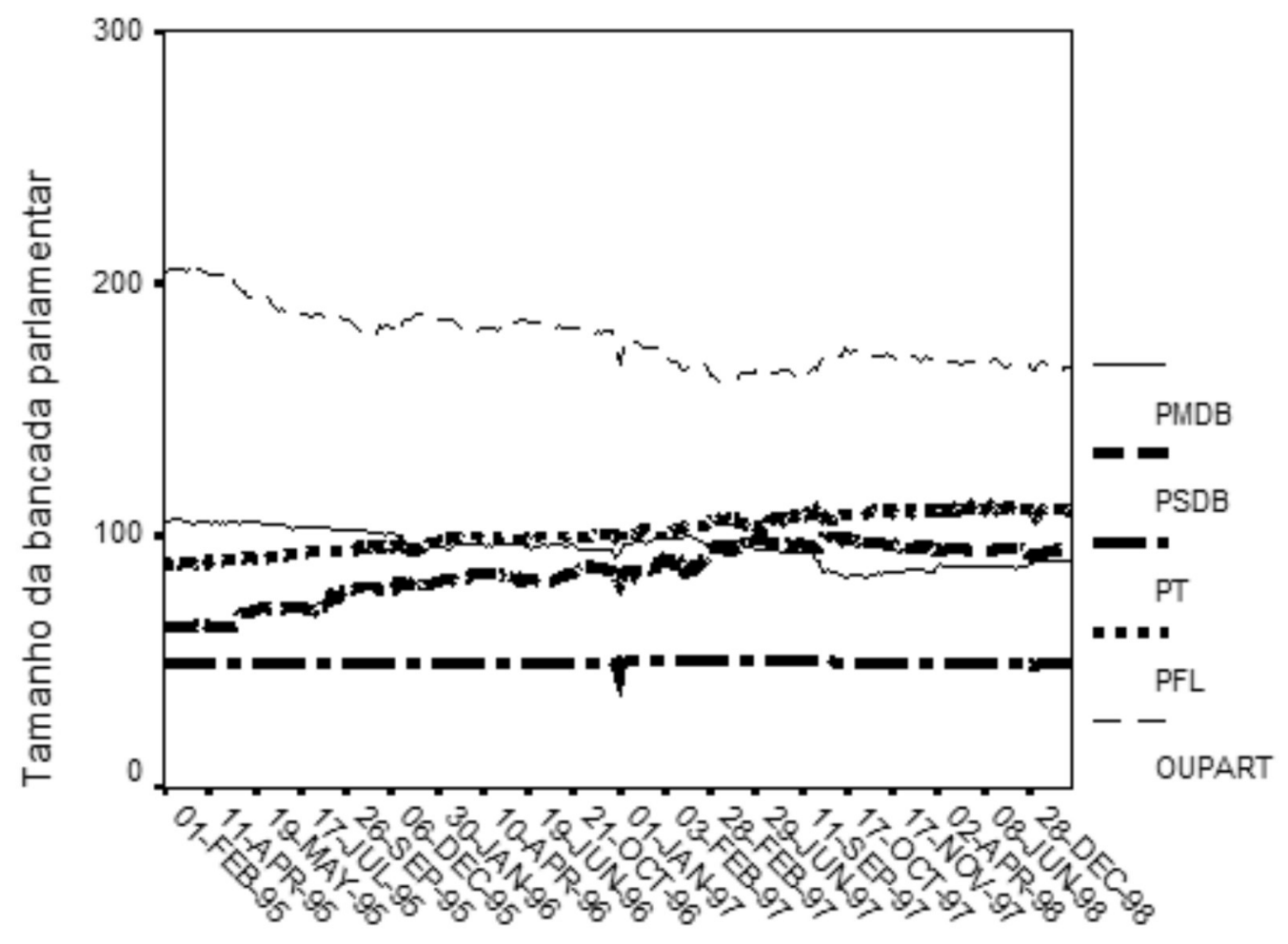

Período

FONTE: o autor, a partir de Câmara dos Deputados (2007).

Contudo, outro padrão foi observado entre 1999 e 2002, conforme descreve o Gráfico 2. Nesse período foi realizado o segundo mandato, e o primeiro de um Presidente reeleito pelo voto em ambos os pleitos, de Fernando Henrique Cardoso. O Partido dos Trabalhadores manteve-se praticamente constante, enquanto a grande bancada dos pequenos partidos teve dois comportamentos bem distintos antes e depois das eleições municipais de 2000. No biênio 1999-2000, ocorreram oscilações a partir de 2000; este agregado cresceu de maneira constante até o ano eleitoral de 2002. 
GRÁFICO 2 - VARIAÇÕES DIA-A-DIANOS TAMANHOS DAS BANCADAS PARTIDÁRIAS NA CÂMARA DOS DEPUTADOS (1999-2002)

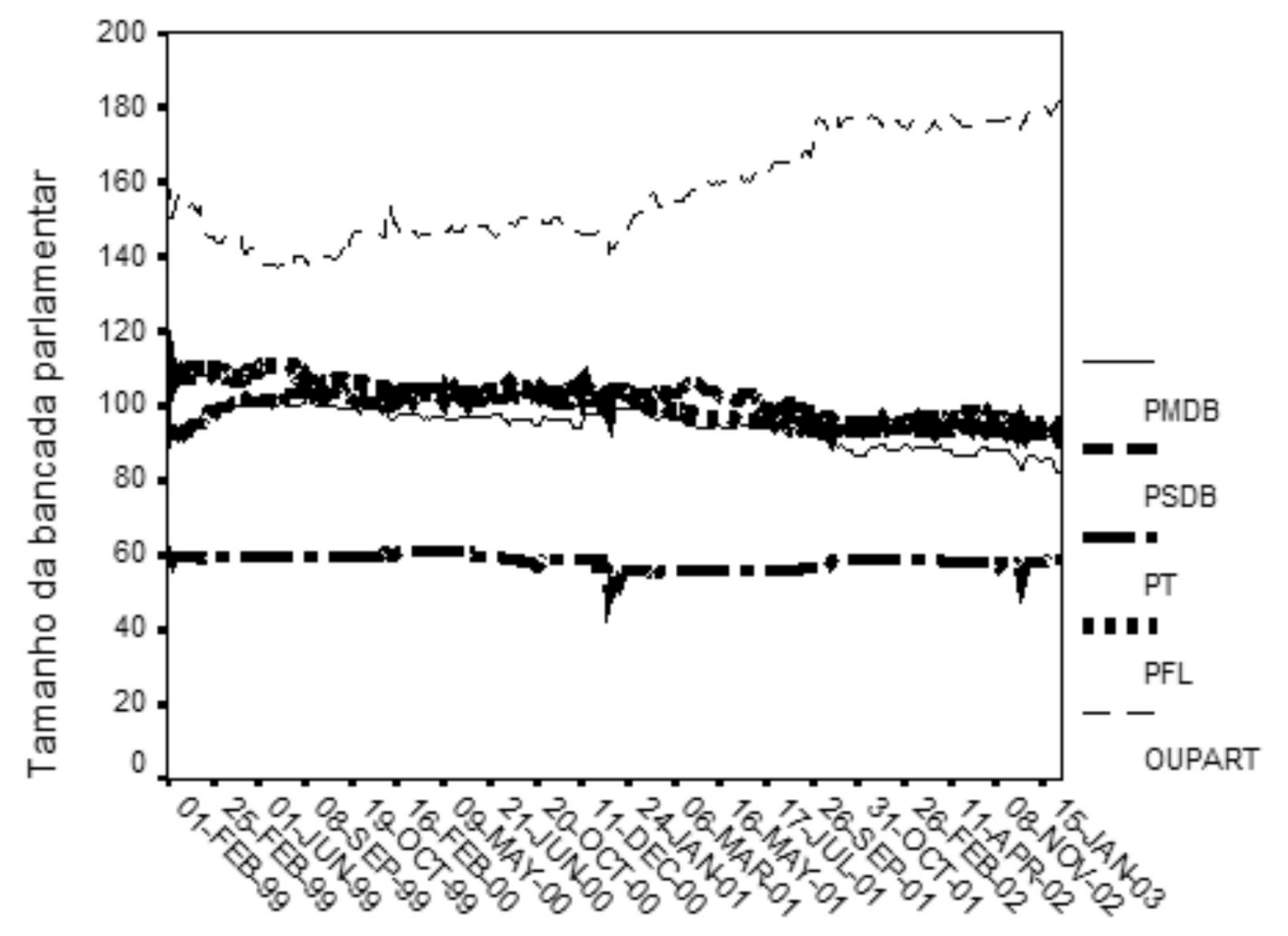

Período

FONTE: o autor, a partir de Câmara dos Deputados (2007)

No período de 2003 a 2006, o PMDB e o PT formaram uma aliança governamental de apoio ao governo de centro-esquerda de Lula, sendo os dois principais partidos dessa composição. Eles tiveram o mesmo tamanho de bancada na data de 21 de dezembro de 2005 , mas a posição de primeira ou segunda bancada foi revezada entre essas duas agremiações partidárias. Contudo, os gráficos 1 , 2 e 3 revelam que, excluindo a estabilidade da coalizão governamental e as variações da diária migração partidária, cada legislatura teve um padrão distinto de variação dia-a-dia nos tamanhos das quatro maiores bancadas e da outra bancada, a dos outros partidos. 


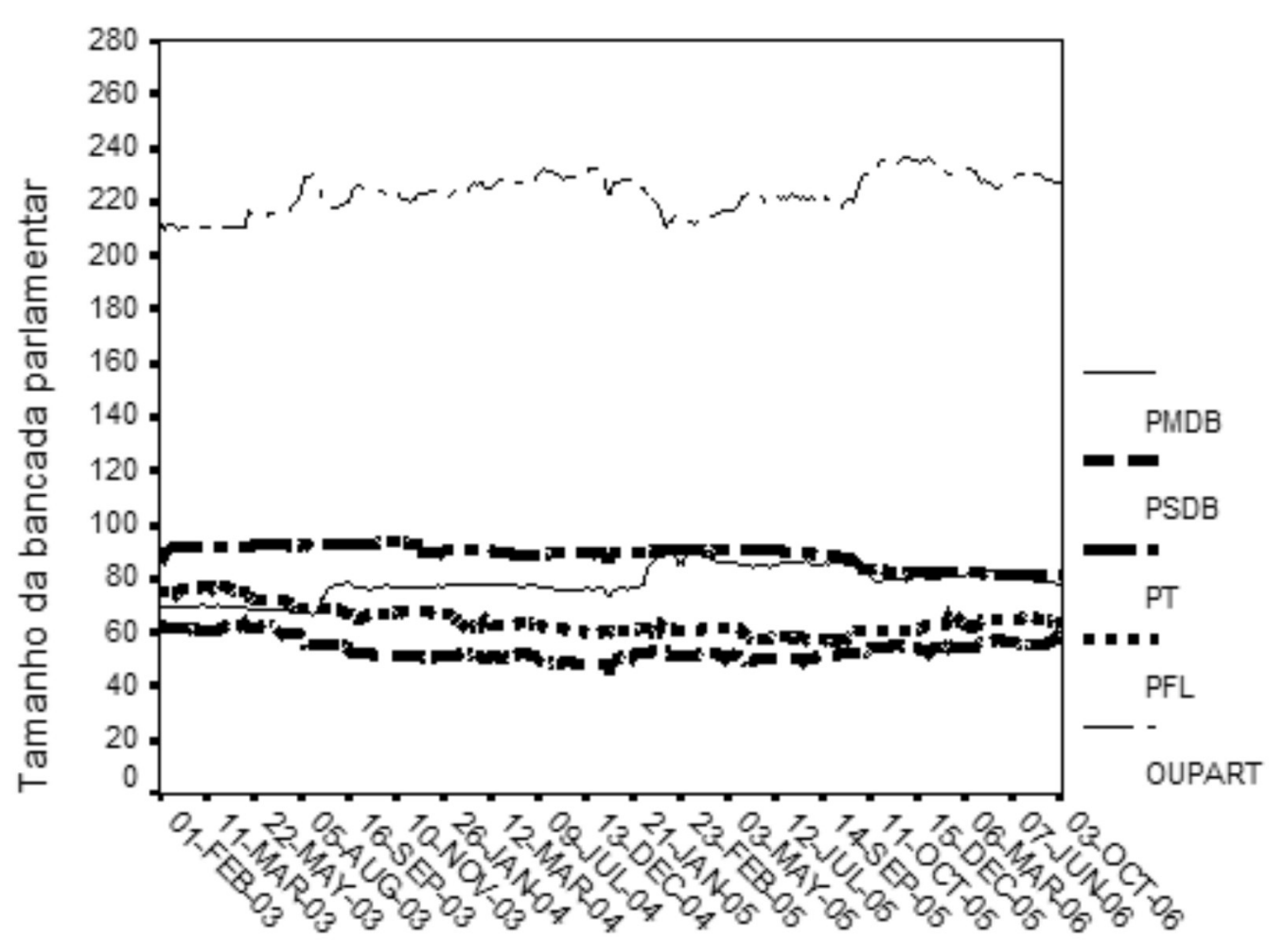

Período

FONTE: o autor, a partir de Câmara dos Deputados (2007)

Por outro lado, os outros partidos apresentam uma enorme variação, no agregado, do tamanho das suas bancadas. Logo, o estudo aqui apresentado corrobora os achados da pesquisa de Roma: "O argumento a ser desenvolvido é o de que a infidelidade partidária na Câmara dos Deputados é menos prejudicial ao sistema representativo do que se estabelece por convenção. [...] Além disso, as mudanças de partido revelam-se consistentes do ponto de vista ideológico. Os migrantes escolhem, dentre as diversas alternativas de filiação, aquela com uma ideologia semelhante à do partido de origem e repetem, no partido de destino, seu ideário e seu modo de votar. Eles trocam de partido, mas, na prática, continuam marcando a mesma posição política. Somente uma pequena minoria transita entre os blocos ideológicos e muda o seu comportamento, desvirtuando a representação da preferência dos seus eleitores" (ROMA, 2007, p. 354).

\section{CONCLUSÕES}

A literatura acadêmica que trata a migração partidária como um fator de instabilidade política (MELO, 2004, p. 161), indica que a elevada taxa de migração afeta a governabilidade porque esse processo alteraria a correlação de forças no interior da Câmara dos Deputados. Isso tornaria a coalizão governista mais instável do que seria em um cenário em que a migração partidária fosse reduzida.

O presente estudo critica o argumento apresentado de que a migração partidária afeta a estrutura de poder na Câmara dos Deputados. Os principais achados deste trabalho podem ser resumidos em dois pontos.

O primeiro é a existência de dois padrões de bancadas partidárias: os grandes e os pequenos partidos. No agregado, os grandes partidos tendem a ter pequenas oscilações na variação dia- 
a-dia, enquanto o agregado dos outros partidos unidos, para fins metodológicos em uma única bancada, tendem a ter um dispersão maior. Além disso, a oscilação na bancada dos pequenos partidos tende a ser maior no período entre as eleições municipais e a presidencial, período em que essa bancada aumenta de tamanho ao mesmo tempo em que acontecem pequenas reduções nas bancadas dos grandes partidos - no caso da legislatura 1999-2002; enquanto o período de 1995-1999 ocorreu um pequeno aumento nas três maiores bancadas e uma significativa redução na macro bancada dos pequeno partidos. Em todas as legislaturas destaca-se o PT, que sempre teve um número quase constante no tamanho da bancada, mas passou a ter uma oscilação maior quando passou a fazer parte da coalizão do governo.

O segundo refere-se à composição partidária de três das maiores instâncias hierárquicas na Câmara dos Deputados, a Mesa Diretora, as presidências da CCJR e a CFT que corresponde anoa-ano aos respectivos tamanhos das quatro maiores bancadas, ou seja, a correlação de forças é diretamente proporcional às quantidades de parlamentares de cada agremiação partidária com mai- or poder no período de 1995 a 2006, ou seja: o PMDB, o PSDB, o PT e o PFL.

Ao contrário do ponto exposto por Melo, defendemos que, apesar da intensa variação no tamanho das bancadas, ou seja, da migração partidária, os principais postos de poder na Câmara dos Deputados continuaram na esfera dos maiores partidos da coalizão política, dos quais destacamos a Presidência, a Primeira Vice-Presidência e a Presidência da Comissão de Constituição e Justiça ou da Comissão de Finanças e Tributação, postos que continuam em poder dos principais partidos da coalizão de apoio ao governo, independentemente da migração partidária ocorrida no período de 1995 a 2006

Conclui-se, portanto, que a migração partidária não afeta os tamanhos das quatro principais bancadas de uma forma que haja alterações nos postos da Mesa Diretora ou das Comissões de Finanças e Tributação ou Constituição e Justiça e Cidadania - coerente com os achados da pesquisa de Roma (2007, p. 380), que aponta que as conseqüências da migração partidária no sistema representativo não têm o impacto ressaltado pela literatura baseada na "magnitude e nas motivações das mudanças de legenda" (ibidem).

Marcelo Costa Ferreira (m.ferreira@unifesp.br) é Doutor em Ciência Política pela Pontifícia Universidade Católica de São Paulo (PUC-SP) e Professor de Ciência Política na Universidade Federal de São Paulo (Unifesp).

\section{REFERÊNCIAS BIBLIOGRÁFICAS}

ARAUJO, M. 2002. Mudanças partidárias. A evolução das migrações partidárias na Câmara dos Deputados (1979-1999). São Paulo. Dissertação (Mestrado em Ciência Política). Universidade de São Paulo.

DINIZ, S. 2000. Migrações partidárias e o calendário eleitoral. Revista de Sociologia e Politica, Curitiba, n. 15, p. 31-48, nov. Disponível em: http://www.scielo.br/pdf/rsocp/n15/ a03n15.pdf. Acesso em: 2.jan.2010.

FONSECA, S. F. \& MARTINS, G. A. 1982. Curso de Estatística. São Paulo: Atlas.

FREITAS, A. M. 2008. Infidelidade partidária e representação política: alguns argumentos sobre a migração partidária no Brasil. Caderno
CHR, Salvador, v. 21, n. 52, p. 37-45. Disponível em: http://www.cadernocrh.ufba.br/ include/getdoc.php?id=1781\&article $=$ $545 \&$ mode $=$ pdf $\&$ OJSSID $=3$ c605c7e02ba 9 e2dfce5b6fca0f5e568. Acesso em: 2.jan.2010.

MARENCO, A. M. 2001. Sedimentação de lealdades partidárias no Brasil: tendências e descompassos. Revista Brasileira de Ciências Sociais, São Paulo, v. 16, n. 45, p. 93-113. fev. Disponível em: http://www.scielo.br/pdf/ rbcsoc/v16n45/4331.pdf. Acesso em: 2.jan. 2010

MARENCO, A. M \& SERNA, M. 2007. Por que carreiras políticas na esquerda e direita não são iguais? Recrutamento legislativo no Brasil, Chile e Uruguai. Revista Brasileira de Ciências So- 
ciais, São Paulo, v. 22, n. 64, p. 93-113, jun. Disponível em: http://www.scielo.br/pdf/ rbcsoc/v22n64/a08v2264.pdf. Acesso em: 2.jan.2010.

MELO, C. R. F. 2004. Retirando as cadeiras do lugar: migração partidária na Câmara dos Deputados 1985/2002. Belo Horizonte: UFMG.

ROMA, C. 2007. Os efeitos da migração interpartidária na conduta parlamentar. Dados,
Rio de Janeiro, v. 50, p. 351-392. Disponível em: http://www.scielo.br/pdf/dados/v50n2/ a05v50n2.pdf. Acesso em: 2.jan.2010.

SCHIMITT, R. A. 1999. Migração partidária e reeleição na Câmara dos Deputados. Novos Estudos, São Paulo, n. 54, p. 127-146, jul.

TUFTE, E. 2001. The Visual Display of Quantitative Information. Cheshire: Graphics.

\section{OUTRAS FONTES}

CÂMARA DOS DEPUTADOS. 2007. Relatório da variação diária da composição das bancadas partidárias. Arquivo magnético. Brasília, Distrito Federal.

2008. Regimento Interno da Câmara dos Deputados: Resolução n 17/1989, atualizado até a Resolução 34/2005. Brasília: Câmara dos Deputados.
TRIBUNAL SUPERIOR ELEITORAL. Evolução do eleitorado. Sítio do Tribunal Superior Eleitoral, seção "Eleições", subseção "Estatísticas do eleitorado". Disponível em: http:// www.tse.jus.br/internet/eleicoes/ regi_uf_blank.htm. Acesso em: 2.jan.2010. 

REPRESENTATIVES (1995-2006)

\section{Marcelo Costa Ferreira}

Academic literature has emphasized the fact that high rates of political party migration within the House of Representatives would undermine the Brazilian political party system and provoke political instability by making coalitions within parliament fragile. The research question behind this article involves analysis of the relationship between party migration and the correlation of forces within the House of Representatives. In order to move our research agenda forward, we look at the daily variation of party migrations, measuring this indirectly by looking at the variation of party benches, between 1995 and 2006, comparing them to the party composition of executive boards and presidencies of the Commissions on the Constitution and Justice and on Finances and Taxation. . Our major finding is that high rates of political party migration have an impact on the smaller party benches, but do not affect the sizes of the four larges benches to a degree that could alter the correlation of forces within the House of Representatives. Such a discovery runs counter to the relationship that has been put forth by the critics of party migration within Brazil, regarding high rates of migration and political instability within the House of Representatives.

KEYWORDS: Political Party Migration; Brazilian Politics; House of Representatives. 


\section{Marcelo Costa Ferreira}

La littérature académique souligne le fait que les taux élevés de migration partidaire politique dans la Chambre des Députés dénatureraient le système partidaire brésilien et provoqueraient de l'instabilité politique, car les coalitions à l'intérieur du parlement brésilien seraient devenues instables. La question proposée par cet article est l'analyse de la relation entre la migration et la corrélation de forces à l'intérieur de la Chambre des Députés. Pour le faire, nous considérons la variation quotidienne des migrations partidaires, mesurées indirectement par la variation des dimensions des ensembles de députés, entre 1995 et 2006, en les comparant avec les compositions partidaires des ensembles administratifs et des présidences des Comités de Constitution et Justice et de Finances et Fiscalité. La principale conclusion de cette étude est que la forte migration partidaire a un impact sur les petits ensembles partidaires, mais elle n'affecte pas les dimensions des quatre plus grands ensembles dans une proportion qui puisse altérer la corrélation de forces à l'intérieur de la Chambre des Députés. Cette découverte contrarie la relation proposée par les critiques de la migration partidaire au Brésil, entre une forte migration et l'instabilité politique dans la Chambre des Députés.

MOTS-CLES: migration partidaire; politique brésilienne; Chambre des Députés. 